\title{
Utilization and cost of antibacterial drugs in 2 general surgery units in Palestine measured using anatomical therapeutic chemical classification and defined daily dose methodology
}

W.M. Sweileh, ${ }^{7}$ S.O. Adas, ${ }^{1}$ A. F. Sawalha' and A.S. Abu Taha ${ }^{7}$

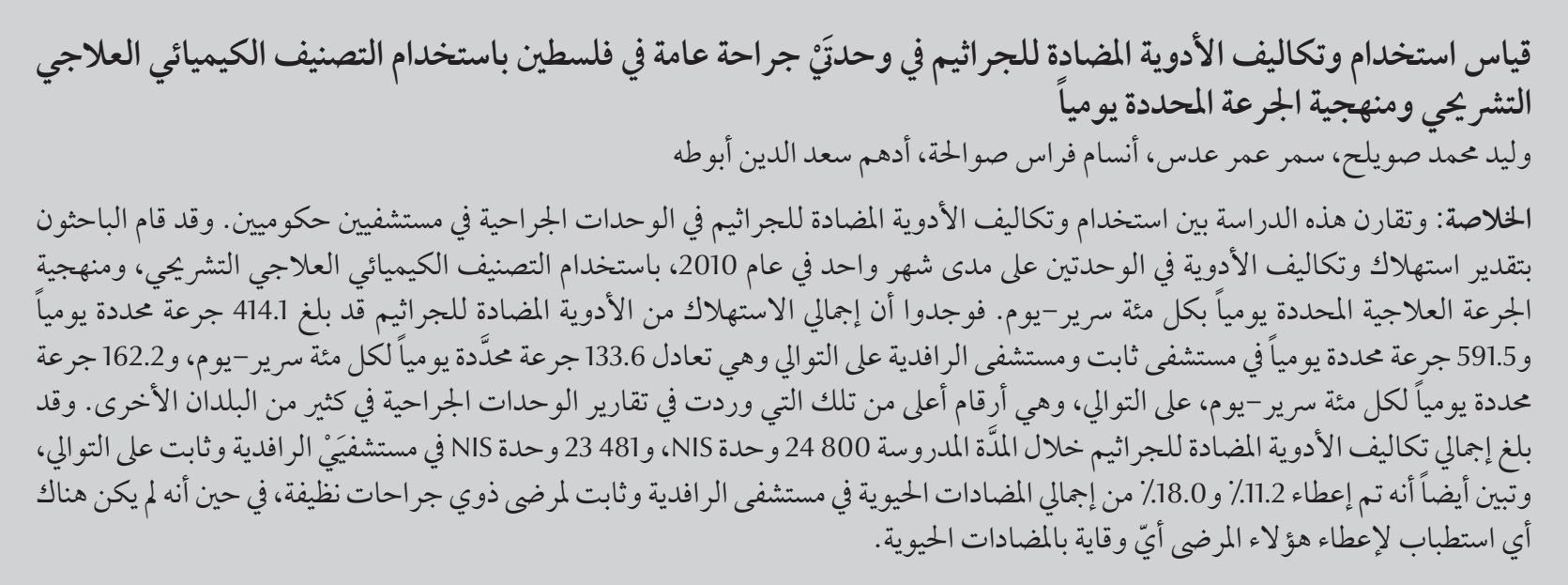

ABSTRACT This study compared the utilization and cost of antibacterial agents in surgical units of 2 government hospitals in Palestine. The consumption and cost of drugs was estimated in the units over a 1-month period in 2010 using the anatomical therapeutic chemical classification and defined daily doses (DDD) per 100 bed-days. The total consumption of antibacterial agents was 414.1 DDD and 591.5 DDD at Thabet and Rafidia hospitals respectively. These corresponded to 133.6 DDD/100 bed-days and 162.2 DDD/100 bed-days respectively, figures that were higher than those reported in surgical units in many other countries. Total cost of antibacterial agents during the study period was 24800 and 23481 NIS for Rafidia and Thabet hospitals respectively. Approximately $11.2 \%$ and $18.0 \%$ of the total antibiotic DDD in Rafidia and Thabet hospitals were given to patients with clean surgeries in which antibiotic prophylaxis is not indicated.

Utilisation et coût des antibactériens dans deux services de chirurgie générale en Palestine, mesurés à l'aide du système de classification anatomique, thérapeutique et chimique et de la méthodologie des doses thérapeutiques quotidiennes

RÉSUMÉ La présente étude a comparé l'utilisation et le coût des agents antibactériens dans des services de chirurgie de deux hôpitaux publics en Palestine. La consommation et le coût des médicaments dans les services ont été estimés sur une période d'un mois en 2010 à l'aide du système de classification anatomique, thérapeutique et chimique et des doses thérapeutiques quotidiennes calculées pour 100 jours-patient. La consommation totale des agents antibactériens était de 414,1 doses thérapeutiques quotidiennes dans l'hôpital de Thabet et de 591,5 doses thérapeutiques quotidiennes dans l'hôpital de Rafidia. Elles correspondaient à 133,6 doses thérapeutiques quotidiennes pour 100 jours-patient et à 162,2 doses thérapeutiques quotidiennes pour 100 jours-patient, respectivement. Ces chiffres sont supérieurs à ceux transmis par les services de chirurgie de nombreux autres pays. Le coût total des agents antibactériens pendant la période de l'étude était 24800 et 23481 nouveaux shekels israéliens pour les hôpitaux de Rafidia et Thabet, respectivement. Environ 11,2 \% et 18,0 \% des doses thérapeutiques quotidiennes totales d'antibiotiques dans les hôpitaux de Rafidia et de Thabet ont été administrées à des patients subissant une intervention chirurgicale propre pour lesquelles une antibioprophylaxie n'était pas nécessaire. 


\section{Introduction}

The misuse of antimicrobial agents has led to a rise in the number and types of resistant microorganisms. The Mediterranean region has been identified as an area of hyper-endemicity for multi-resistant hospital pathogens [1]. This is particularly the case for methicillin-resistant Staphylococcus aureus (MRSA) and applies to both the European and nonEuropean countries of the Mediterranean region [2].

To assess drug utilization, a drug classification system is needed to facilitate data collection. The most widely used system is the anatomical therapeutic chemical (ATC) classification and defined daily dose (DDD), which is now used by the World Health Organization (WHO) Collaborating Centre for International Drug Monitoring in Europe [3]. In hospital studies the average number of DDD per bed-day is used for comparisons between hospitals. Other indicators for assessing the general quality of drug prescribing habits are the number of drugs accounting for $90 \%$ of drug use [the drug utilization 90\% (DU90\%)] and for $90 \%$ of drug costs (DC90\%) [4].

Monitoring of drug use in only one hospital might be inadequate, as interdepartmental differences in drug use may exist. Therefore, comparisons with other hospitals and between departments in which similar medical disorders are treated should be used in the evaluation of the quality of pharmacotherapy. Comparisons between similar services in different institutions may yield useful information that will help in defining rational antibiotic use in both institutions.

The objective of this study was to assess and compare the utilization pattern and cost of antibacterial agents between general surgical units in 2 governmental hospitals in Palestine.

\section{Methods}

\section{Study setting and sample}

This study was carried out in the surgical units of Rafidia hospital in Nablus city and Martyr Thabet Thabet hospital in Tulkarm city, Palestine. Selection of these 2 hospitals was based on the fact that they are the only government hospitals with general surgical units in the Nablus and Tulkaram districts of Palestine. Over a 1-month period in June 2010 the researchers visited both units daily and analysed the medical files of all patients admitted during the study period. Data collection was made after written approval from the Ministry of Health to carry out the project and verbal approval from each patient. Patients' files were not analysed retrospectively; rather, each patient was followed up until discharge.

\section{Data collection}

Each drug prescribed was recorded using its generic name and ATC code. Topical antibiotics were not included. Paediatric surgery was excluded because of a lack of accurate paediatric DDD. The standard pharmacy protocol in both hospitals requires that hospital physicians prescribe antibiotics for individual patients, but there are no restrictions on antibiotic use.

Patient details, including age, sex, type of surgical procedures and length of hospital stay, were entered into a specially-designed proforma. The type of surgery and the antibiotics prescribed during the patients' hospital stay along with the dose, frequency, duration and route of administration were also recorded. Based on the National Research Council wound classification for antimicrobial prophylaxis in surgery, surgeries were classified as clean, clean-contaminated, contaminated or dirty [5].

The following indicators were calculated:
- DDD for each prescribed antibacterial agent and the total DDD for antibacterial agents prescribed in each surgical department.

- DDD per 100 bed-days. A bed-day was defined as the number of patients in the hospital or each ward per day and was calculated by multiplying the number of admissions by the average length of stay. We followed the World Health Organization DDD/ ATC system recommendation for calculation of bed-days in which the day of admission and discharge were counted as one single day [3].

- DU90\% index was calculated by ranking the antibiotics by volume of DDD, summing the DDD for these drugs and then determining how many drugs accounted for $90 \%$ of drug use [4].

- DC90\% index was calculated in a similar way to DU90\% by ranking the antibiotics and determining how many drugs accounted for $90 \%$ of costs. The costs of medications were obtained from the hospital pharmacy. Costs are presented in new Israel shekels (NIS) (NIS 1= US\$ 0.27).

\section{Data analysis}

Statistical was carried out using SPSS for Windows, version 16. Independent sample Student $t$-test was used to compare continuous variables in the 2 surgical units.

\section{Results}

During the study period, a total of 200 patients were admitted to the surgical units in the 2 hospitals and were followed up for antibacterial drug use. Details about the 2 hospitals and the types of surgical proceduresincluded in the analysis are shown in Table 1. The most common surgical procedures in both units were appendectomy, cholecystectomy, colorectal, hernioplasty and mastectomy. No statistically significant difference was found between 


\begin{tabular}{|c|c|c|}
\hline Variable & Thabet hospital & Rafidia hospital \\
\hline \multicolumn{3}{|l|}{ Hospital characteristics } \\
\hline Total beds (no.) & 110 & 205 \\
\hline Beds in surgical unit (no.) & 42 & 44 \\
\hline Surgical units (no.) & 7 & 11 \\
\hline Pharmacists and pharmacy technicians (no.) & 8 & 10 \\
\hline Patients admitted during study period (no.) & 100 & 100 \\
\hline Total bed-days during study period (no.) & 308 & 365 \\
\hline $\begin{array}{l}\text { Mean (SD) length of hospital stay (days/ } \\
\text { patient) }\end{array}$ & $3.08(2.34)$ & $3.65(2.52)$ \\
\hline \multicolumn{3}{|l|}{ Patient characteristics } \\
\hline$\%$ male & 53 & 46 \\
\hline Mean (SD) age (years) & $36.0(16.0)$ & $36.4(18.6)$ \\
\hline \multicolumn{3}{|l|}{ Type of surgery ${ }^{a}(\%)$} \\
\hline Appendectomy & 40 & 42 \\
\hline Cholecystectomy & 11 & 13 \\
\hline Hernioplasty & 18 & 9 \\
\hline Mastectomy & 2 & 4 \\
\hline \multicolumn{3}{|l|}{ Prescribing indices } \\
\hline Total DDD (no.) & 414.1 & 592.0 \\
\hline DDD per 100 bed-days (no.) & 133.6 & 162.2 \\
\hline DU90\% drugs/total drugs (no.) & $4 / 9$ & $5 / 8$ \\
\hline Total drugs in DU90\% segment (no.) & 395.1 & 570.1 \\
\hline Total cost of DU90\% drugs (NIS) & 23222 & 23484 \\
\hline Total cost of DC90\% drugs (NIS) & 22862 & 23014 \\
\hline
\end{tabular}

${ }^{a}$ Most common operations.

$S D=$ standard deviation; $D D D=$ defined daily dose $;$ DU90\% = drug utilization $90 \%$ index; $D C 90 \%=$ drug cost $90 \%$ index; NIS = new Israeli shekels.

the length of patient's hospital stay in the 2 units [3.08 (SD 2,4) versus 3.65 (SD 2.5) days]. Similarly, there was no statistically significant difference in the mean age of patients attending both units $[36.4$ (SD 18.6) versus 36.0 (SD 16.0) years]. During the study period, no deaths were registered in either unit.

Table 2 displays the total DDD of the various antibacterial agents utilized in the 2 surgical units. There were 5 drugs in the DU90\% segment out of the total of 9 in both hospitals. The DU90\% index placed metronidazole injection in the first place in Thabet and Rafidia hospitals with 140.3 and 227.2 DDD respectively. Cefuroxime came in second in both surgical units with 125.3 and 131.8 DDD in Thabet and
DC90\% segment out of the total of 9 in both hospitals. The total medication costs calculated from the DC90\% segment at Thabet (23222 NIS) and Rafidia hospitals (23 484 NIS) were not significantly different.

Analysis of antibiotic administration in Thabet hospital showed that of 45 patients who received prophylactic preoperative antibiotics, 10 of them had clean surgery. The DDD of antibiotics given to patients with clean surgeries was 74.6 out of the total DDD of 414.1 (18.0\%) (Table 4). In Thabet hospital, 34 patients did not receive indicated prophylaxis, 23 of them had clean-contaminated, 8 had contaminated and 3 had dirty surgery. Post-operatively, antibiotics were given to 73 patients: 30 patients were given antibiotics for 3 days, 35 patients for 2 days and 8 patients for 10 days.

Analysis of antibiotic administration in Rafedia hospital showed that of 61 patients who received prophylactic preoperative antibiotic, 12 of them had clean surgery. The DDD of antibiotics given to patients with clean surgeries in Rafidia hospital was 66.1 out of the total of 591.5 (11.2\%) (Table 4). In this hospital 34 patients did not receive the indicated antibiotic prophylaxis: 20 had clean-contaminated, 10 had contaminated and 4 had dirty surgery. Post-operatively, 77 patients were given antibiotics: 37 patients for 3 days, 25 for 5 days and 4 patients for 12 days.

Table 5 shows the distribution of the most utilized antibacterials and their DDD by type of surgery at Thabet and Rafidia hospitals.

Figure 1 shows a comparison of antibacterial agents used in the current study in Palestine, in 2 hospitals in the Islamic Republic of Iran and 3 other European hospitals. The figure shows that the total DDD/100 bed-days in general surgical units was the highest in Palestine compared with the other countries. 


\begin{tabular}{|c|c|c|c|c|c|c|c|}
\hline & Thabet hospi & & & & Rafidia hospi & & \\
\hline Antibacterial drug & ATC code & $\begin{array}{l}\text { Total DDD } \\
\text { (no.) }\end{array}$ & $\%$ & Antibacterial drug & ATC code & $\begin{array}{l}\text { Total DDD } \\
\text { (no.) }\end{array}$ & $\%$ \\
\hline Metronidazole ${ }^{a}$ & (J01XD01) & $140.3^{\mathrm{a}}$ & 33.9 & Metronidazole ${ }^{\mathrm{a}}$ & (J01XD01) & $227.2^{\mathrm{a}}$ & 38.4 \\
\hline Cefuroxime $^{a}$ & (J01DD04) & $125.3^{\mathrm{a}}$ & 30.3 & Cefuroxime $^{\mathrm{a}}$ & (J01DD04) & $131.8^{\mathrm{a}}$ & 22.3 \\
\hline Ceftriaxone $\mathrm{e}^{\mathrm{a}}$ & (J01DD04) & $75.5^{\mathrm{a}}$ & 18.2 & Ceftriaxone $\mathrm{e}^{\mathrm{a}}$ & (J01DD04) & $114.0^{\mathrm{a}}$ & 19.3 \\
\hline Gentamicin $^{\mathrm{a}}$ & (J01GB03) & $31.6^{\mathrm{a}}$ & 7.6 & Ampicillin ${ }^{a}$ & (J01CA01) & $55.9^{\mathrm{a}}$ & 9.5 \\
\hline Meropenem & (J01DH02) & 22.3 & 5.4 & Gentamicin $^{a}$ & (J01GB03) & $41.2^{\mathrm{a}}$ & 7.0 \\
\hline Ampicillin & (J01CA01) & 15.3 & 3.7 & Meropenem & (J01DH02) & 14.5 & 2.5 \\
\hline Ciprofloxacin & (J01MA02) & 2.0 & 0.5 & Erythromycin & (J01FA01) & 3.5 & 0.6 \\
\hline Cephalexin & (J01DB01) & 1.0 & 0.2 & Cefazoline & (J01DB04) & 3.3 & 0.6 \\
\hline Cloxacillin & (J01CF02) & 0.8 & 0.2 & - & - & - & - \\
\hline Total & - & 414.1 & 100.0 & Total & - & 591.5 & 100.0 \\
\hline
\end{tabular}

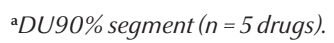

\section{Discussion}

In this descriptive prospective study, the utilization of antibacterial agents (J01 class) was compared between the surgical units of 2 governmental hospitals using the WHO ATC/DDD methodology. No statistically significant difference in antibiotic utilization was found between the 2 units when measured by DDD/100 bed days. However, the total DDD of antibacterial agents utilized was more than $100 \mathrm{DDD} / 100 \mathrm{BD}$ in both units. A closer analysis is needed to identify the reasons for the relatively high utilization of antibacterial agents, and measures are needed to rationalize their use. A study carried out in governmental hospitals of Gaza Strip, Palestine, on bacterial isolates from clinical sources including urine, pus, blood and cerebrospinal fluid found high bacterial resistance to common antibiotics [6]. Another study on paediatric patients at Al-Watani government hospital found a high resistance rate of Streptococcus pneumoniae to most antibacterial drug classes [7], while a study in the department of internal medicine at Al-Watani governmental hospital in Nablus, Palestine revealed that the use of antibacterial agents was less than optimal [8]. It has been found that implementation of an antimicrobial prescribing improvement programme can lead to substantial savings in antimicrobial use and expenditures and decreased rates of certain nosocomial infections due to resistant microorganisms [9].

In our study, the mostly commonly used agent in both wards, according to the DDD and DU 90\% index, was metronidazole, followed by cefuroxime and ceftriaxone. The number of antibacterial agents which accounted for the DU90\%

\begin{tabular}{|c|c|c|c|c|c|c|c|}
\hline \multicolumn{4}{|c|}{ Thabet hospital } & \multicolumn{4}{|c|}{ Rafidia hospital } \\
\hline Antibacterial drug & ATC code & $\begin{array}{l}\text { Total cost } \\
\text { (NIS) }\end{array}$ & $\%$ & Antibacterial drug & ATC code & $\begin{array}{l}\text { Total cost } \\
\text { (NIS) }\end{array}$ & $\%$ \\
\hline Cefuroxime $^{a}$ & (J01DD04) & $9827^{a}$ & 41.8 & Cefuroxime $^{\mathrm{a}}$ & (J01DD04) & $10335^{\mathrm{a}}$ & 41.7 \\
\hline Meropenem $^{\mathrm{a}}$ & (J01DH02) & $8455^{a}$ & 36.0 & Meropenem ${ }^{a}$ & (J01DH02) & $5510^{a}$ & 22.2 \\
\hline Metronidazole $^{a}$ & (J01XD01) & $2315^{\mathrm{a}}$ & 9.9 & Metronidazole $^{\mathrm{a}}$ & (J01XD01) & $3749^{a}$ & 15.1 \\
\hline Ceftraiaxone $^{\mathrm{a}}$ & (J01XD01) & $2265^{a}$ & 9.6 & Ceftriaxone $^{a}$ & (J01DD04) & $3420^{a}$ & 13.8 \\
\hline Gentamicin & (J01GB03) & 361 & 1.5 & Gentamicin & (J01GB03) & 470 & 1.9 \\
\hline Ampicillin & (J01CA01) & 244 & 1.0 & Ampicillin & (J01CA01) & 895 & 3.6 \\
\hline Ciprofloxacin & (J01MA02) & 7 & $<0.1$ & Cefazolin & (J01DB04) & 200 & 0.8 \\
\hline Cephalexin & (J01DB01) & 4 & $<0.1$ & Erythromycin & (J01FA01) & 221 & 0.8 \\
\hline Cloxacillin & (J01CF02) & 4 & $<0.1$ & - & - & - & - \\
\hline Total & - & 23482 & 100.0 & Total & - & 24800 & 100.0 \\
\hline
\end{tabular}

${ }^{a}$ DC90\% segment ( $n=4$ drugs). 


\begin{tabular}{|c|c|c|c|c|c|c|}
\hline \multirow[t]{2}{*}{ Type of surgery } & \multicolumn{2}{|c|}{$\%$ of operations } & \multicolumn{2}{|c|}{$\begin{array}{l}\text { Patients receiving } \\
\text { prophylactic preoperative } \\
\text { antibacterial (no.) }\end{array}$} & \multicolumn{2}{|c|}{$\begin{array}{l}\text { Total DDD } \\
\text { (no.) }\end{array}$} \\
\hline & Thabet & Rafidia & Thabet & Rafidia & Thabet & Rafidia \\
\hline Clean & 31 & 17 & 10 & 12 & 74.6 & 66.1 \\
\hline Clean-contaminated & 51 & 59 & 28 & 39 & 217.8 & 313.6 \\
\hline Contaminated & 10 & 16 & 2 & 6 & 52.4 & 100.8 \\
\hline Dirty & 8 & 8 & 5 & 4 & 69.3 & 111.0 \\
\hline Total & 100 & 100 & 45 & 61 & 414.1 & 591.5 \\
\hline
\end{tabular}

index was 5 in both units. This small number and lack of diversity of antibacterial agents in Palestinian government hospitals could be due to the limited types of antibacterial agents available in the hospital pharmacy. The dependence of the Palestinian Ministry of Health on donations from European countries or local pharmaceutical companies has led to intensive use of similar kinds antibacterial agents for potentially different types of infections or procedures.

A previous study at the internal medicine department of Al-Watani governmental hospital indicated that utilization of antibacterial agents reached a total of $39 \mathrm{DDD} / 100$ beddays [8]. This is lower than that reported in the surgical units in this study. This is expected since antibiotics are more commonly utilized as prophylaxis in surgical units than in internal medicine departments. In a study carried out in Sari Emam hospital, Islamic Republic of Iran, the total DDD/100 bed-days in general surgery was 121 in 2000 and this declined to 107 in 2005 [10]. Our results are also higher than those reported from surgical departments in hospitals in Spain, Estonia and Sweden [11]. Unfortunately, no data in this regard are available from other neighbouring countries to include in the analysis.

The difference between the results of our study and those published from other countries may be attributed to lack of infection control and prevention programmes, as well as lack of special guidelines for antibiotic use in surgical units. Another potential reason is that surgeons in both units tend not to rely on the results of microbiological cultures, but instead rely on clinical judgement in conjunction with the proven effectiveness of antimicrobial agents that offer a broad spectrum to cover against likely pathogens. Further studies on all units and from a large number of hospitals in Palestine are needed to be able to better analyse the antibacterial utilization in hospitals and to compare it with other countries.

Antimicrobial administration is not recommended for all surgical procedures. Typically, prophylactic antimicrobials are not indicated for clean surgeries [5]. They are particularly beneficial in surgical procedures associated with a high rate of infection and the agent chosen should have

\begin{tabular}{|c|c|c|c|c|}
\hline \multirow[t]{2}{*}{ Type of surgery } & \multicolumn{2}{|c|}{ Thabet hospital } & \multicolumn{2}{|c|}{ Rafidia hospital } \\
\hline & $\begin{array}{l}\text { Most utilized } \\
\text { antibacterials }\end{array}$ & $\begin{array}{l}\text { Total DDD } \\
\text { (no.) }\end{array}$ & $\begin{array}{l}\text { Most utilized } \\
\text { antibacterials }\end{array}$ & $\begin{array}{l}\text { Total DDD } \\
\text { (no.) }\end{array}$ \\
\hline \multirow[t]{3}{*}{ Clean } & Cefuroxime & 43.3 & Cefuroxime & 29.4 \\
\hline & Ceftriaxone & 15.0 & Metronidazole & 8.7 \\
\hline & Metronidazole & 5.7 & Ceftriaxone & 8.0 \\
\hline \multirow[t]{3}{*}{ Clean-contaminated } & Metronidazole & 93.7 & Metronidazole & 139.3 \\
\hline & Cefuroxime & 62.3 & Cefuroxime & 85.5 \\
\hline & Ceftriaxone & 55.5 & Ceftriaxone & 58.0 \\
\hline \multirow[t]{3}{*}{ Contaminated } & Metronidazole & 24.0 & Metronidazole & 38.1 \\
\hline & Ampicillin & 10.3 & Ceftriaxone & 18.5 \\
\hline & Gentamicin & 9.7 & Ampicillin & 17.8 \\
\hline \multirow[t]{3}{*}{ Dirty } & Meropenem & 17.5 & Metronidazole & 38.6 \\
\hline & Metronidazole & 17.0 & Ceftriaxone & 24.5 \\
\hline & Ceftriaxone & 11.0 & Ampicillin & 22.0 \\
\hline
\end{tabular}




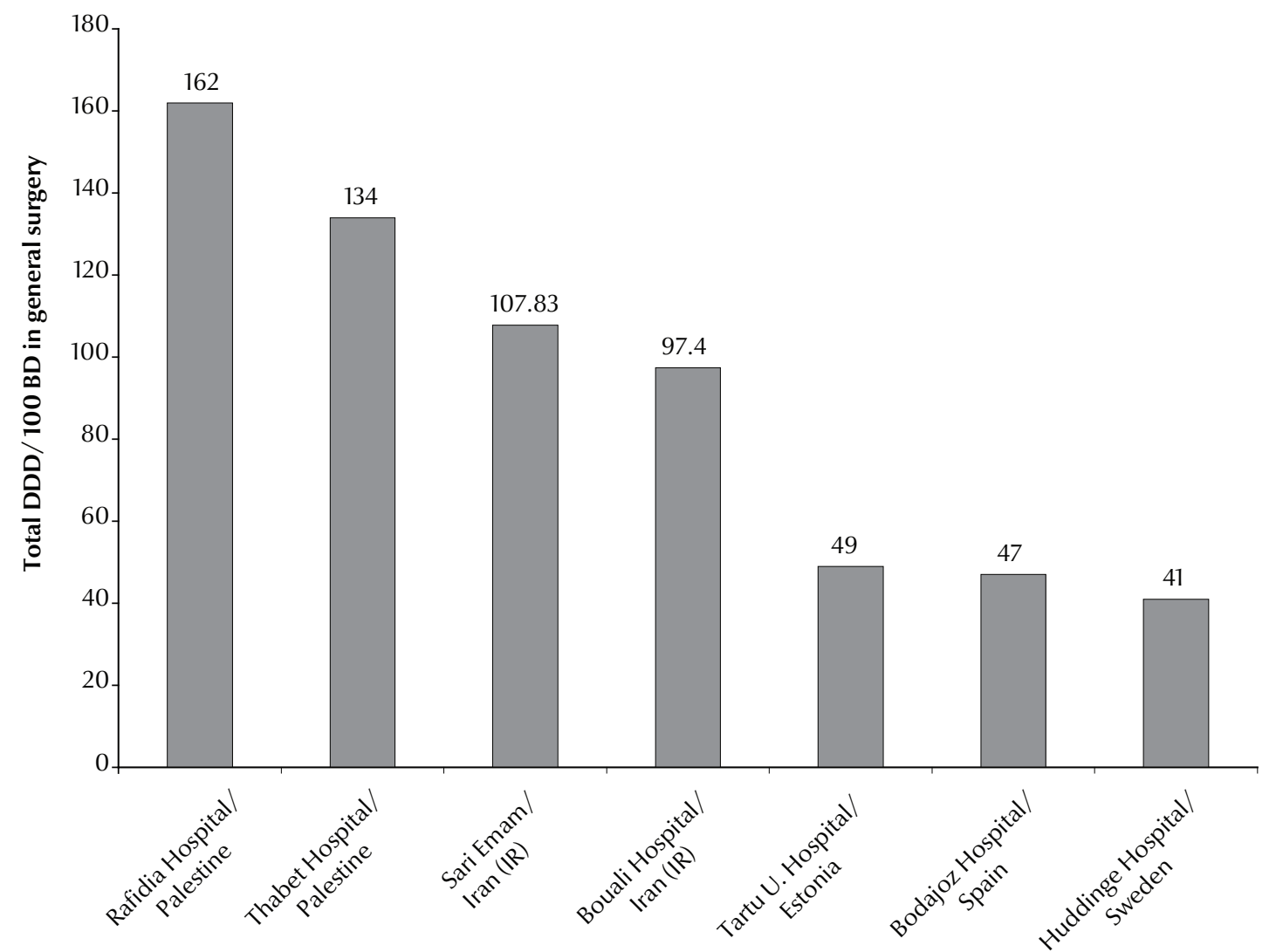

Figure 1 Use of systemic antibacterial agents in surgical units of 2 hospitals in Palestine, 2 hospitals in Islamic Republic of Iran [10] and 3 hospitals in Europe [11] measured in defined daily doses (DDD)/100 bed-days

activity against the most common surgical wound pathogens. Cephalosporins (such as cefazolin) are appropriate firstline agents for most surgical procedures, targeting the most likely organisms $[5,12]$. It is advisable to avoid broadspectrum antimicrobial therapy that may lead to the development of antimicrobial resistance [13]. In our study, $11.2 \%$ and $18.0 \%$ of the total antibiotic DDD in Rafedia and Thabet hospitals respectively were administered to patients with clean surgeries. This suggests that these antibiotics were not being appropriately used. Furthermore, the most used antibiotics in both wards according to the DU90\% index were metronidazole and the cephalosporins cefuroxime (2nd generation) and ceftriaxone (3rd generation). They were used as first-line empirical treatment either preoperatively or postoperatively for short-term treatment despite possible narrower spectrum alternatives being adequate.

In conclusion, our study showed that consumption of antibacterial agents in surgical unit in Palestine was relatively high. The study emphasizes the need for national antibiotic policies and education programs in infection control and prevention for the health care professionals.

\section{References}

1. Gür D, Unal S. Resistance to antimicrobial agents in Mediterranean countries. International Journal of Antimicrobial Agents, 2001, 17:21-26.

2. Tiemersma EW et al.; European Antimicrobial Resistance Surveillance System Participants. Methicillin-resistant Staphylococcus aureus in Europe, 1999-2002. Emerging Infectious Diseases, 2004, 10:1627-1634.

3. Guidelines for ATC Classification and DDD Assignment. Oslo, WHO Collaborating Centre for Drug Statistics and Methodology, 2010.
4. Bergman $U$ et al. Drug utilization $90 \%$-a simple method for assessing the quality of drug prescribing. European Journal of Clinical Pharmacology, 1998, 54(2):113-118.

5. Cruse PJ, Foord R. The epidemiology of wound infection. A 10-year prospective study of 62,939 wounds. Surgical Clinics of North America. 1980, 60(1):27-40.

6. El Astal Z. Bacterial pathogens and their antimicrobial susceptibility in Gaza Strip, Palestine. Pakistan Journal of Medical Sciences, 2004, 20:365-370. 
7. Adwan $\mathrm{K}$ et al. High incidence of penicillin resistance amongst clinical isolates of Streptococcus pneumoniae in northern Palestine. Journal of Medical Microbiology, 1999, 48:1107-1110.

8. Sweileh $\mathrm{W}$ et al. Utilization of anti-infective agents measured in "defined daily dose" (DDD): a study in Palestine. Islamic University Journal, 2007, 15:59-66.

9. Frank MO et al. Decrease in expenditures and selected nosocomial infections following implementation of an antimicrobial-prescribing improvement program. Clinical Performance and Quality Health Care, 1997, 5:180-188.

10. Ebrahimzadeh MA, Shokrzadeh M, Ramezani A. Utilization pattern of antibiotics in different wards of specialized Sari
Emam university hospital in Iran. Pakistan Journal of Biological Sciences, 2008, 11:275-279.

11. Kiivet RA et al. Antibiotic use in 3 European university hospitals. Scandinavian Journal of Infectious Diseases, 1998, 30:277-280.

12. Bratzler DW et al. Antimicrobial prophylaxis for surgery: an advisory statement from the National Surgical Infection Prevention Project. Clinical Infectious Diseases, 2004, 38(12):1706-1715.

13. Bratzler DW, Houck PM, Surgical Infection Prevention Guideline Writers Workgroup. Antimicrobial prophylaxis for surgery: an advisory statement from the National Surgical Infection Prevention Project. American Journal of Surgery, 2005, 189:395404.

\section{The evolving threat of antimicrobial resistance}

Antimicrobial resistance (AMR) is not a recent phenomenon, but it is a critical health issue today. Over several decades, to varying degrees, bacteria causing common infections have developed resistance to each new antibiotic, and AMR has evolved to become a worldwide health threat. With a dearth of new antibiotics coming to market, the need for action to avert a developing global crisis in health care is increasingly urgent.

The World Health Organization has long recognized AMR as a growing global health threat, and the World Health Assembly, through several resolutions over two decades, has called upon Member States and the international community to take measures to curtail the emergence and spread of AMR. The WHO Global strategy for the containment of antimicrobial resistance, published in 2001, set out a comprehensive set of recommendations for AMR control which remain valid today. The evolving threat of antimicrobial resistance examines the experiences with implementing some of those recommendations 10 years on, the lessons learnt along the way and the remaining gaps.

Further information about this and other WHO publications is available at: http://apps.who.int/bookorders/anglais/ homel.jsp 